\title{
Assessment of light history indicators for predicting seagrass biomass
}

\author{
M. P. Adams ${ }^{\text {a }}$, A. J. P. Ferguson ${ }^{\text {b }}$, C. J. Collier ${ }^{\text {c, d, M. E. Baird }}{ }^{\text {e }}$, R. K. Gruber ${ }^{\text {f, }}{ }^{\text {and }}$ K. R. O'Brien $^{\text {a }}$ \\ ${ }^{a}$ School of Chemical Engineering, The University of Queensland, St Lucia, Queensland, 4072 \\ ${ }^{\mathrm{b}}$ NSW Office of Environment and Heritage, Sydney, New South Wales, 2000 \\ ${ }^{\mathrm{c}}$ School of Marine and Tropical Biology, James Cook University, Townsville, Queensland, 4811 \\ ${ }^{\mathrm{d}}$ Centre for Tropical Water and Aquatic Ecosystem Research (TropWATER), James Cook University, Cairns, \\ Queensland, 4870

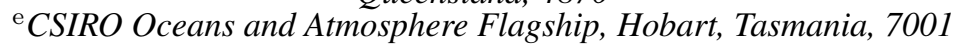 \\ ${ }^{\mathrm{f}}$ School of Earth and Environment, The University of Western Australia, Crawley, Western Australia, 6009 \\ g Oceans Institute, The University of Western Australia, Crawley, Western Australia, 6009 \\ Email: m.adams5@uq.edu.au
}

\begin{abstract}
Seagrasses are rapidly declining worldwide due to anthropogenic impacts on coastal environments. One major contributor to seagrass loss is the degradation of water quality which reduces light availability.

In this paper we use a data-driven approach to compare several indicators of light history for their ability to predict seagrass biomass. Data sets for daily light and seasonal biomass of seagrass (Zostera muelleri) meadows from two lakes (Lake Macquarie and Tuggerah Lake) in New South Wales, Australia, were analysed. The light history indicators were compared to seagrass biomass, for different periods of light history. Three indicators were tested: (1) an unweighted mean of the light history, (2) a weighted mean of the light history that places greater emphasis on the more recent light doses, and (3) a modified rolling average of light history.

For the time periods that maximised the correlation between seagrass biomass and light history (hereafter called the optimised light history periods), the relationships between seagrass biomass and the three measures of light history always showed high significance $(\mathrm{p}<0.05)$ but low predictive power $\left(\mathrm{R}^{2}<0.5\right)$. Our results consistently demonstrated that there was a significant and positive relationship between light history and biomass at the optimised light history periods. However, light availability was clearly not the only factor influencing seagrass biomass in the two lakes studied. The best correlations were identified for total and below-ground biomass in Lake Macquarie $\left(\mathrm{R}^{2}=0.47-0.49, \mathrm{p}<0.0001\right)$; this was attributed to the high below-ground to aboveground biomass ratio and lesser influence of sediment and nutrient conditions in Lake Macquarie compared to Tuggerah Lake.
\end{abstract}

All three light history indicators yielded similar correlations between biomass and light history (maximum variation in $\mathrm{R}^{2}$ was 0.05 ). Indicator 1 was slightly better than the other two because it produced higher $\mathrm{R}^{2}$ values and lower p-values. Indicator 1 was also easier to calculate than indicator 2 and requires a shorter time period of daily light data to optimise than indicator 2 . Indicator 3 is ideally suited for use as a tracer in large-scale modelling simulations, and thus may be used in these simulations if indicator 1 cannot be easily calculated. Hence we generally recommend indicator 1, although indicator 3 may also be suitable in some circumstances. For these two indicators, 1.5-8 months of daily light data was required to optimise the correlation between biomass and light history for the seagrass Z. muelleri in Lake Macquarie and Tuggerah Lake. These time periods provide an upper limit on the time that this seagrass species should be subjected to light deprivation before management actions are triggered.

Keywords: Light history, biomass, management, monitoring, seagrass 


\section{INTRODUCTION}

Seagrasses are an aquatic plant functional group that are threatened worldwide by several anthropogenic impacts, of which the most common is the degradation of water quality (Waycott et al., 2009). Several physical, geological and geochemical factors influence the spatial distribution of seagrass (Koch, 2001), but the most important environmental factor affecting seagrass survival is light availability (Ralph et al., 2007). Once seagrasses are lost, they can take a decade (McGlathery et al., 2012) or longer to recover (Cunha et al., 2004). Hence, it is vital for environmental monitoring programs to identify potential seagrass losses before they occur. This requires a knowledge of the relevant time periods over which seagrass biomass changes with light availability.

For seagrass monitoring programs on the eastern coast of Australia, the light history period over the past 2-4 weeks has been used to identify when light availability drops below the minimum light requirements of seagrass (Chartrand et al., 2012; McKenzie et al., 2014). A light history period of 2 weeks coincides with the time required for the most fragile seagrass species to undergo complete shoot loss due to severe light deprivation (Collier et al., submitted). In contrast, a 4 week light history period corresponds to both the tidal cycle (and hence eliminates the natural light variability associated with tides) and the approximate time taken for seagrass leaves on a shoot to be fully replaced (Collier et al., 2012b). Light levels over these sub-monthly time periods have been compared with minimum light requirements of seagrass calculated from observations made over the longer time period of 3 months (Collier et al., 2012a).

In this paper, we compare three indicators of light history for their ability to predict changes in the biomass of the seagrass species Zostera muelleri present in two lakes in New South Wales, Australia. This analysis identifies correlations between the light history indicators and viable seagrass biomass only, as none of the seagrass underwent complete shoot loss during the experimental study period. The tested indicators range from an unweighted mean to a modified rolling average of light history. We identify the relative merits of each of these indicators, and the light history time period that best correlates with changes in seagrass biomass. The implications of our results for seagrass monitoring programs is also explained.

\section{LIGHT HISTORY INDICATORS}

Three light history indicators were investigated for their potential to predict seagrass biomass and identify the timescale of light history, $\tau$ (in units of $\mathrm{d}$ ), that best correlates with seagrass biomass.

Light history indicator 1 is the simplest of the three, and represents the mean of the daily light dose received over the past $\tau$ days. This indicator is denoted as $I_{\text {hist,1 }}$, and its value on day $t+1$ is equal to

$$
\left(I_{\mathrm{hist}, 1}\right)_{t+1}=\frac{1}{\tau} \sum_{n=1}^{\tau} I_{t-\tau+n}
$$

where $I_{t}$ is the daily light dose received on day $t$.

Light history indicator 2 is a linear weighted mean of the daily light received over the past $\tau$ days, and places greater weighting on the light doses received more recently. This indicator is denoted as $I_{\text {hist,2}}$, and its value on day $t+1$ is equal to

$$
\left(I_{\text {hist }, 2}\right)_{t+1}=\sum_{n=1}^{\tau}\left(n \times I_{t-\tau+n}\right) / \sum_{n=1}^{\tau} n,
$$

where $I_{t}$ is the daily light dose received on day $t$.

Light history indicator 3 represents a modified rolling average of light history, on the timescale of $\tau$ days. This indicator is denoted as $I_{\text {hist }, 3}$, and its value on day $t+1$ is calculated from its value on day $t$ and the light received on the previous day, $I_{t}$ :

$$
\left(I_{\text {hist }, 3}\right)_{t+1}=\frac{1}{\tau}\left((\tau-1)\left(I_{\text {hist }, 3}\right)_{t}+I_{t}\right) .
$$

Light history indicator 3 is the discrete approximation of an ordinary differential equation for light history. This can be seen by rearranging equation (3) for the subject $\left(I_{\text {hist }, 3}\right)_{t+1}-\left(I_{\text {hist }, 3}\right)_{t}$,

$$
\left(I_{\text {hist }, 3}\right)_{t+1}-\left(I_{\text {hist }, 3}\right)_{t}=\frac{1}{\tau}\left(I_{t}-\left(I_{\text {hist }, 3}\right)_{t}\right),
$$


and identifying that the left side of this rearranged equation represents the change in light history over one day, $\Delta I_{\text {hist,3 }} / \Delta t$, where $\Delta t=1 \mathrm{~d}$. Hence, equation (3) is the discrete approximation of

$$
\frac{\mathrm{d} I_{\text {hist }}}{\mathrm{d} t}=\frac{1}{\tau}\left(I-I_{\text {hist }}\right)
$$

where $I$ is the current daily light dose and $I_{\text {hist }, 3}$ is replaced by $I_{\text {hist }}$ for notational simplicity. This equation has been previously used to represent photoacclimation and/or light history kinetics in phytoplankton (Post et al., 1984), corals (Anthony and Hoegh-Guldberg, 2003) and seagrass (Adams et al., 2015).

\section{METHODS}

Study site. Lake Macquarie (mean depth of $8 \mathrm{~m}$ ) and Tuggerah Lake (mean depth of $2.8 \mathrm{~m}$ ) are located on the central coast of New South Wales, approximately $85 \mathrm{~km}$ north of Sydney. The region experiences a warm temperate climate, with most rainfall occurring from late summer to autumn. The dominant seagrass species, Z. muelleri, is restricted to shallow lake margins in both systems. Maps of the lakes, including sites where water quality and seagrass biomass were measured, are provided in Ferguson et al. (submitted).

Data collection. Daily surface light dose was determined from daily global solar exposure (GSE) measurements made between 2006 to 2012 inclusive. This data was obtained from the Australian Government Bureau of Meterology (BOM) website (www.bom.gov.au/climate/data/) for the station "Swansea (Catherine St)" (site number: 061377, latitude: $33.0933^{\circ} \mathrm{S}$, longitude: $151.6317^{\circ} \mathrm{E}$ ). The GSE measurements from the BOM Swansea (Catherine St) station were assumed to represent the daily surface light dose at all sites within Lake Macquarie and Tuggerah Lake. These GSE measurements $\left(\mathrm{MJ} \mathrm{m}^{-2} \mathrm{~d}^{-1}\right)$ were converted to surface dose of photosynthetically active radiation, $I_{\text {surface }}\left(\mathrm{mol} \mathrm{m}^{-2} \mathrm{~d}^{-1}\right)$, using the conversion factor $0.5639 \mathrm{MJ} \mathrm{mol}^{-1}$ (Grinham, 2007). There were 18 days in the 2006-2012 period that daily GSE measurements were not available at the BOM Swansea (Catherine St) station. The largest period of unavailable consecutive GSE measurements was 12 days. For time periods where GSE measurements were not available, the missing values were linearly interpolated from the GSE measurements made on the days immediately before and after the time periods of missing GSE data.

Secchi depth was recorded at 6 sites within Lake Macquarie and 3 sites within Tuggerah Lake. Both lakes are microtidal, so the Secchi depth measurements were assumed to be unaffected by tidal cycles. For each of these 9 sites, the median Secchi depth was calculated from at least 15 monthly measurements made from December 2011 onwards (Ferguson et al., submitted). The Secchi depth was assumed to be spatially variable but temporally constant, because Secchi depth and seagrass biomass measurements were collected in different time periods (see below). To explore the validity of this assumption, we repeated the analysis described in this paper for temporally variable Secchi depth, by assuming that monthly measurements of Secchi depth made in 2012 represent the annual cycle of Secchi depth from 2006 to 2012 inclusive. In this additional analysis, the strengths of correlation identified between seagrass biomass and light history were not substantially affected by the inclusion of temporal variation in Secchi depth (maximum change in $\mathrm{R}^{2}$ values was 0.07 ), and for the best correlations $\left(\mathrm{R}^{2}>0.4\right)$ the predicted optimised light history period changed by at most one month (data not shown). Hence, the assumption of temporally (but not spatially) constant Secchi depth did not substantially affect the conclusions of this paper. The 9 median Secchi depth values $z_{\mathrm{SD}}(\mathrm{m})$ were converted to attenuation coefficients $K_{d}\left(\mathrm{~m}^{-1}\right)$ by use of the empirical formula $K_{d}=\lambda / z_{\mathrm{SD}}$, where $\lambda=1.42$ was chosen (Ferguson et al., submitted). Median Secchi depths were always smaller in Tuggerah Lake (1.5-1.7 m) than in Lake Macquarie (1.7-5.3 m), indicating that the water was more turbid in Tuggerah Lake.

Above-ground and below-ground biomass was measured at 8 sites within Lake Macquarie and 4 sites within Tuggerah Lake. These 12 "biomass" sites were not necessarily co-located with the 9 "water quality" sites where Secchi depth measurements were made. However, for each of the 12 biomass sites, the closest water quality site was identified for later calculations of the seagrass canopy light dose. At each biomass site, seagrass samples were collected from up to 5 depths (ranging from $0.3-4 \mathrm{~m}$, measured with respect to the Australian Height Datum) in up to 5 seasons: early spring (September 2010), late spring (October-November 2010), summer (January-February 2011), autumn (May 2011) and winter (July 2011). Due to logistics, it was not possible to sample all sites in all seasons. Seagrass samples were collected in triplicate, and the above-ground and below-ground biomass were separated to measure their dry weight (DW) in units of g DW $\mathrm{m}^{-2}$ (details provided in Ferguson et al., submitted). Overall, 60 and 39 triplicate measurements of seagrass biomass were made in Lake Macquarie and Tuggerah Lake, respectively. For each triplicate measurement, the mean above-ground and below-ground biomass, site, date, and depth at the seagrass canopy, was recorded. 
Data analysis. For each biomass site, depth and date, the light dose $I_{t}$ at the seagrass canopy on date $t$ was calculated from: the surface light dose $\left(I_{\text {surface }}\right)_{t}$ at the BOM Swansea (Catherine St) station on date $t$, the attenuation coefficient $K_{d}$ calculated for the water quality site nearest to the biomass site, and the depth at the top of the seagrass canopy $z$, using the Beer-Lambert function,

$$
I_{t}=\left(I_{\text {surface }}\right)_{t} \exp \left(-K_{d} z\right) \text {. }
$$

The time series of seagrass canopy light dose $I_{t}$ was then used to calculate the three light history indicators $I_{\text {hist, } 1}, I_{\text {hist }, 2}$ and $I_{\text {hist }, 3}$ according to equations (1)-(3), for values of the light history timescale $\tau$ ranging from 7-365 days to compare timescales ranging from weekly to annually. For indicator 3 , which is a modified rolling average that depends on the light history indicator value from the the previous day, the initial value of $I_{\text {hist, } 3}$ at 1 January 2006 was set equal to the seagrass canopy light dose $I_{t}$ on this day to provide a $>3.5$ year lead-in period for this iteratively-calculated indicator (the first biomass measurements were obtained more than 3.5 years later, in September 2010). For each of the two lakes (Tuggerah and Macquarie), the strength and statistical significance of the linear relationship between biomass and light history was identified for total, above-ground and below-ground biomass, each of the three light history indicators, and all timescales $\tau$ ranging from 7-365 days, using the correlation coefficient $\mathrm{R}^{2}$ and $\mathrm{p}$-value as metrics for this relationship. For each light history indicator, lake and biomass compartment (above-ground, below-ground and total), the timescale $\tau$ which yielded the highest correlation coefficient was identified and hereafter referred to as the "optimised" timescale of light history.

\section{RESULTS AND DISCUSSION}

At the optimised timescales of light history, the relationships between biomass and light history always demonstrated low predictive power $\left(\mathrm{R}^{2}<0.5\right)$ and high significance $(\mathrm{p}<0.05)$. These results were consistently identified for all biomass compartments tested (above-ground, below-ground and total), both lakes, and all three light history indicators (Table 1). The correlations identified between biomass and light history were always positive at the optimised timescales (Lake Macquarie in Figure 1d-f; Tuggerah Lakes in Figure 2d-f). Hence, our analysis indicated that there was a significant and positive relationship between light history and biomass (for optimised $\tau$ ), but the total variance in biomass explained by the estimated bottom light was relatively low. We attributed this result to two causes: (1) our estimates of bottom light dose may possess high uncertainty due to their calculation from Secchi depth measurements, and (2) light is not the only environmental factor that controls seagrass biomass in either of the two lakes.

The highest correlations $\left(\mathrm{R}^{2}=0.47-0.49, \mathrm{p}<0.0001\right)$ were obtained for the below-ground and total biomass versus all three light history indicators in Lake Macquarie (Figure 1a-c, Table 1). In contrast, $\mathrm{R}^{2}$ was less than 0.25 for all biomass compartments and light history indicators tested in Tuggerah Lake (Figure 2a-c, Table 1). Light availability may thus have a greater influence on seagrass biomass in Lake Macquarie than in Tuggerah Lake.

The ratio of below-ground to above-ground seagrass biomass was substantially larger in Lake Macquarie than in Tuggerah Lake. For the sites included in our analysis, the below-ground to above-ground biomass ratio $( \pm \mathrm{SD}$ ) was $6.2 \pm 5.6$ in Lake Macquarie and $1.3 \pm 0.6$ in Tuggerah Lake. This difference in biomass allocation between below-ground and above-ground compartments could be responsible for the higher correlations observed between below-ground biomass and optimised light history in Lake Macquarie $\left(\mathrm{R}^{2}=0.47-0.49\right)$ compared to Tuggerah Lake $\left(\mathrm{R}^{2}=0.13-0.17\right)$. In Tuggerah Lake, the nitrogen concentration, chlorophyll $a$ concentration, fine sediment fraction and turbidity are all significantly higher than in Lake Macquarie (Ferguson et al., submitted). This difference in nutrient and sediment conditions may be responsible for the difference in below-ground to above-ground biomass ratio between the two lakes. The nutrient and sediment conditions may also have a greater influence on seagrass biomass in Tuggerah Lake than in Lake Macquarie; this would explain the lower correlations between biomass and optimised light history observed in Tuggerah Lake.

All three indicators yielded similar correlations between biomass and light history when applied to the same biomass compartment and lake (maximum variation in $\mathrm{R}^{2}$ was 0.05 ). Indicator 1 was slightly better than the other two because it produced higher $\mathrm{R}^{2}$ values and lower $\mathrm{p}$-values (Table 1 ). Indicator 1 was also easier to calculate than indicator 2, and required a shorter time period of light history to optimise the correlation. The latter occurred because indicator 2 provides less weighting to the earlier light history than indicator 1, and thus indicator 2 requires a longer timescale to capture the impact of earlier light history on current seagrass biomass. The light history timescale $\tau$ for indicator 3 cannot be directly compared with indicators 1 and 2 , because it has substantially different physical meaning as defined in Section 2. Indicator 3 is the easiest to 


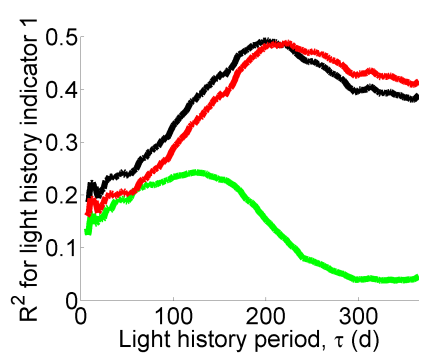

(a) $\mathrm{R}^{2}$ vs light history period $\tau$ for indicator 1 .

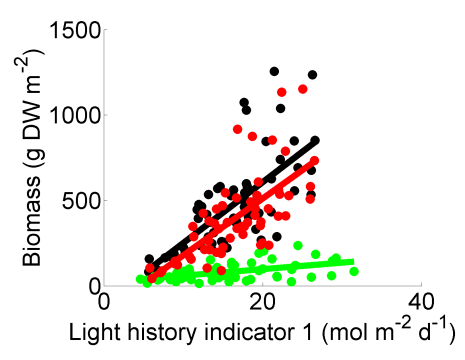

(d) Biomass vs indicator 1 for the light history period $\tau$ with the highest $\mathrm{R}^{2}$.

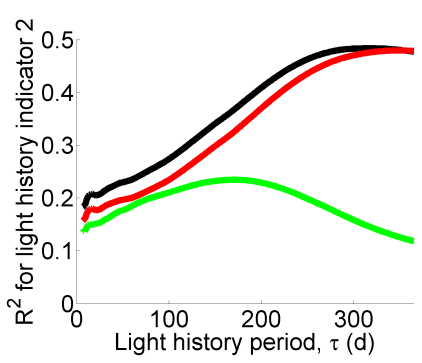

(b) $\mathrm{R}^{2}$ vs light history period $\tau$ for indicator 2 .

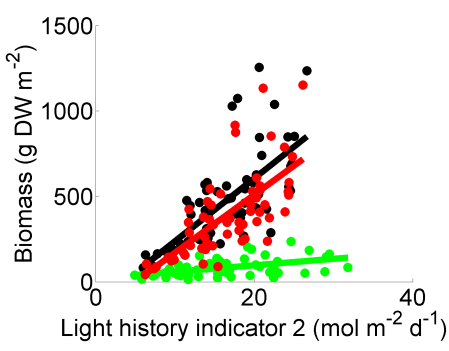

(e) Biomass vs indicator 2 for the light history period $\tau$ with the highest $\mathrm{R}^{2}$.

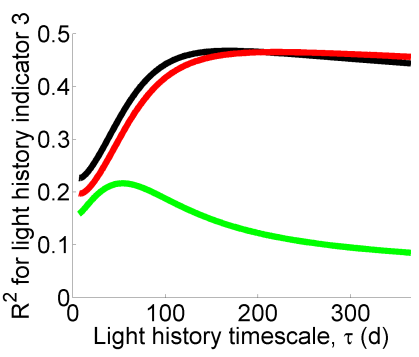

(c) $\mathrm{R}^{2}$ vs light history timescale $\tau$ for indicator 3 .



(f) Biomass vs indicator 3 for the light history timescale $\tau$ with the highest $\mathrm{R}^{2}$.

Figure 1. Correlation of the three light history indicators to above-ground biomass (green), below-ground biomass (red) and total biomass (black), for the seagrass species Zostera muelleri in Lake Macquarie.

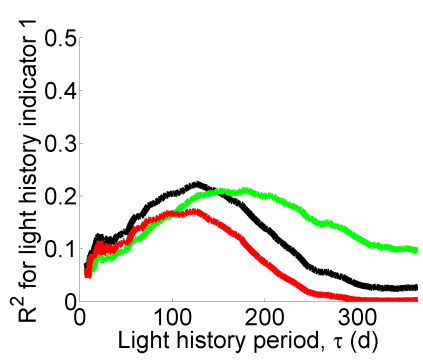

(a) $\mathrm{R}^{2}$ vs light history period $\tau$ for indicator 1 .

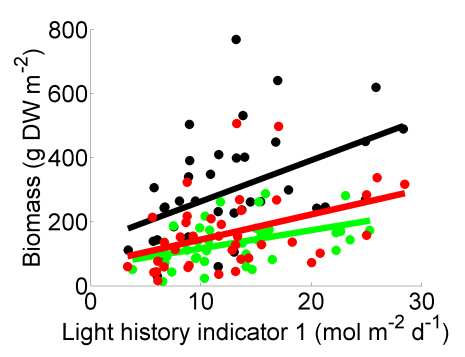

(d) Biomass vs indicator 1 for the light history period $\tau$ with the highest $\mathrm{R}^{2}$.

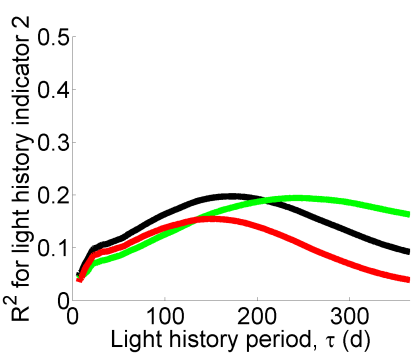

(b) $\mathrm{R}^{2}$ vs light history period $\tau$ for indicator 2 .



(e) Biomass vs indicator 2 for the light history period $\tau$ with the highest $\mathrm{R}^{2}$.

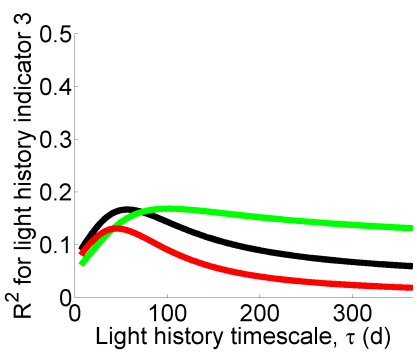

(c) $\mathrm{R}^{2}$ vs light history timescale $\tau$ for indicator 3 .

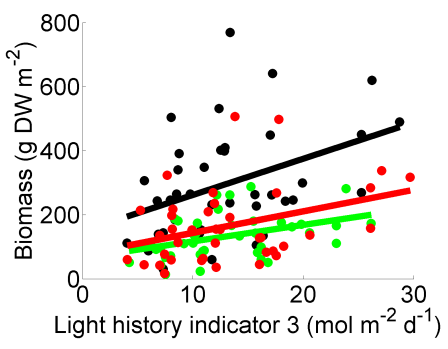

(f) Biomass vs indicator 3 for the light history timescale $\tau$ with the highest $\mathrm{R}^{2}$.

Figure 2. Correlation of the three light history indicators to above-ground biomass (green), below-ground biomass (red) and total biomass (black), for the seagrass species Zostera muelleri in Tuggerah Lake. 
Table 1. Light history timescales $\tau$ that yielded the best correlation between biomass and the three light history indicators, and associated statistics.

\begin{tabular}{lccccccc}
\hline Location & \multicolumn{3}{c}{ Lake Macquarie } & \multicolumn{4}{c}{ Tuggerah Lake } \\
Light history indicator & 1 & 2 & 3 & 1 & 2 & 3 \\
\hline Total biomass: & & & & & & \\
$\quad$ Optimised light history period (d) & 201 & 317 & 169 & 126 & 175 & 57 \\
$\quad \mathrm{R}^{2}$ for optimised light history period & 0.49 & 0.48 & 0.47 & 0.22 & 0.20 & 0.17 \\
$\quad$ p-value for optimised light history period & $<0.0001$ & $<0.0001$ & $<0.0001$ & 0.002 & 0.005 & 0.01 \\
Above-ground biomass: & & & & & & \\
$\quad$ Optimised light history period (d) & 125 & 171 & 54 & 179 & 243 & 102 \\
$\quad \mathrm{R}^{2}$ for optimised light history period & 0.24 & 0.23 & 0.22 & 0.21 & 0.19 & 0.17 \\
$\quad$ p-value for optimised light history period & $<0.0001$ & $<0.0001$ & 0.0002 & 0.003 & 0.005 & 0.01 \\
Below-ground biomass: & & & & & & \\
$\quad$ Optimised light history period (d) & 223 & 349 & 220 & 121 & 151 & 45 \\
$\quad \mathrm{R}^{2}$ for optimised light history period & 0.49 & 0.48 & 0.47 & 0.17 & 0.16 & 0.13 \\
p-value for optimised light history period & $<0.0001$ & $<0.0001$ & $<0.0001$ & 0.009 & 0.01 & 0.02 \\
\hline
\end{tabular}

implement as a tracer in large-scale modelling simulations because its calculation only requires information from the previous day. Hence we generally recommend indicator 1, although indicator 3 may be suitable as a tracer in modelling simulations if indicator 1 cannot be easily calculated.

To identify the best correlation between $Z$. muelleri biomass and light history, our results suggest that daily light data over time periods of 4-8 months and 1.5-8 months are required for indicators 1 and 3 respectively (Table 1). However, because management actions to prevent seagrass decline should be triggered before biomass reductions occur, these periods provide an upper limit on the time that this seagrass species should be exposed to light deprivation before environmental interventions are implemented. Management actions should be triggered well before these time periods have elapsed.

Whilst our study was able to estimate the optimal timescales over which seagrass biomass correlates with light history, it has several limitations. We investigated only one seagrass species (Z. mиelleri); other species will demonstrate different light history responses. For example, we expect that the optimal time period for correlation of seagrass biomass to light history would scale with, but not be identical to, the time to complete shoot loss in extremely low light conditions. While Z. muelleri is projected to require $\approx 30-76$ days to undergo complete shoot loss under severe light deprivation (Collier et al., 2012b, submitted), more fragile seagrass species such as Halophila ovalis may perish after $\approx 17-41$ days (Longstaff and Dennison 1999, Collier et al., submitted). In contrast, larger species such as Posidonia sinuosa may survive low light conditions for up to two years (Collier et al., 2009). Given the large range of timescales over which different seagrass species can respond to changes in light availability, the use of 2-4 weeks for monitoring light conditions of seagrass habitats in environmental management programs (Chartrand et al., 2012; McKenzie et al., 2014) seems appropriate as this time period is sufficiently short to identify when low light levels may induce declines in the most fragile seagrass species (e.g. H. ovalis).

The assumption of temporally constant Secchi depth may introduce uncertainty in the results if there is a clear seasonal pattern in water clarity. Secchi depth does not need to be measured if calibrated light loggers are placed at the seagrass canopy to directly measure canopy light dose. Hence, we recommend that canopy light dose is directly measured in future analyses of the correlation between seagrass biomass and light history.

\section{CONCLUSIONS AND RECOMMENDATIONS}

This study found that three indicators of light history were similar in their ability to identify the correlation between biomass and light history, and that a mean unweighted period of light history (indicator 1) was slightly better than the other two. Whilst light history is a significant predictor of seagrass biomass, it cannot be solely relied upon for biomass predictions, as other environmental factors likely play an important role. For the seagrass species $Z$. muelleri, 1.5-8 months of daily light data was required to maximise the correlation between light history and biomass. These time periods provide an upper limit on the time that this species should be subjected to light deprivation before management actions are implemented, especially because Z. muelleri can undergo complete shoot loss due to severe light deprivation over shorter times $(\approx 30-76$ days). 
M. P. Adams et al., Assessment of light history indicators for predicting seagrass biomass

\section{ACKNOWLEDGEMENT}

The first author would like to thank the financial supports from a University of Queensland Engineering, Architecture and Information Technology (UQ EAIT) Strategic Fellowship.

\section{REFERENCES}

Adams, M. P., A. J. P. Ferguson, P. S. Maxwell, B. A. J. Lawson, J. Samper-Villarreal, and K. R. O’Brien (2015). Light history-dependent respiration explains the hysteresis in the daily ecosystem metabolism of seagrass. Hydrobiologia.

Anthony, K. R. N. and O. Hoegh-Guldberg (2003). Kinetics of photoacclimation in corals. Oecologia 134, 23-31.

Chartrand, K. M., P. J. Ralph, K. Petrou, and M. A. Rasheed (2012). Development of a light-based seagrass management approach for the Gladstone Western Basin Dredging Program. Technical report, Fisheries Queensland, Cairns.

Collier, C. J., M. P. Adams, L. Langlois, M. Waycott, P. S. Maxwell, K. R. O’Brien, and L. McKenzie. Light protection guidelines developed from experimental light response curves for multiple seagrass species (submitted).

Collier, C. J., P. S. Lavery, R. J. Ralph, and R. J. Masini (2009). Shade-induced response and recovery of the seagrass Posidonia sinuosa. Journal of Experimental Marine Biology and Ecology 370, 89-103.

Collier, C. J., M. Waycott, and L. J. McKenzie (2012a). Light thresholds derived from seagrass loss in the coastal zone of the northern Great Barrier Reef, Australia. Ecological Indicators 23, 211-219.

Collier, C. J., M. Waycott, and A. G. Ospina (2012b). Responses of four Indo-West Pacific seagrass species to shading. Marine Pollution Bulletin 65, 342-354.

Cunha, A. H., C. M. Duarte, and D. Krause-Jensen (2004). European Seagrasses: an Introduction to Monitoring and Management, Chapter How long does it take to recolonize seagrass beds?, pp. 72-76. The M\&MS Project.

Ferguson, A. J. P., R. K. Gruber, M. Orr, and P. Scanes. Morphological plasticity in Zostera muelleri across light, sediment, and nutrient gradients in Australian temperate coastal lakes (submitted).

Grinham, A. R. (2007). Downstream effects of land use on shallow-water benthic microalgal communities in Moreton Bay, Australia and Marovo Lagoon, Solomon Islands. Ph. D. thesis, The University of Queensland, Brisbane.

Koch, E. W. (2001). Beyond light: physical, geological, and geochemical parameters as possible submersed aquatic vegetation habitat requirements. Estuaries 24, 1-17.

Longstaff, B. J. and W. C. Dennison (1999). Seagrass survival during pulsed turbidity events: the effects of light deprivation on the seagrasses Halodule pinifolia and Halophila ovalis. Aquatic Botany 65, 105-121.

McGlathery, K. J., L. K. Reynolds, L. W. Cole, R. J. Orth, S. R. Marion, and A. Schwarzschild (2012). Recovery trajectories during state change from bare sediment to eelgrass dominance. Marine Ecology Progress Series 448, 209-221.

McKenzie, L. J., C. Collier, and M. Waycott (2014). Reef Rescue Marine Monitoring Program - Inshore Seagrass, Annual Report for the sampling period 1st July 2011 - 31st May 2012. Technical report, TropWATER, Janes Cook University, Cairns.

Post, A. F., Z. Dubinsky, K. Wyman, and P. G. Falkowski (1984). Kinetics of light-intensity adaptation in a marine planktonic diatom. Marine Biology 83, 231-238.

Ralph, P. J., M. J. Durako, S. Enríquez, C. J. Collier, and M. A. Doblin (2007). Impact of light limitation on seagrasses. Journal of Experimental Marine Biology and Ecology 350, 176-193.

Waycott, M., C. M. Duarte, T. J. B. Carruthers, R. J. Orth, W. C. Dennison, S. Olyarnik, A. Calladine, J. W. Fourqurean, K. L. Heck, A. R. Hughes, G. A. Kendrick, W. J. Kenworthy, F. T. Short, and S. L. Williams (2009). Accelerating loss of seagrasses across the globe threatens coastal ecosystems. Proceedings of the National Academy of Sciences 106, 12377-12381. 